\title{
О ВЛИЯНИИ ИНГИБИТОРА ИЗ БОБОВ СОИ НА ЭНЗИМАТИЧЕСКУЮ АКТИВНОСТЬ И АВТОЛИЗ ТРИПСИНА
}

Натуральные ингибиторы протеолитических ферментов широко распространены в различных органах и тканях животных и растений $\left[{ }^{1-3}\right]$. По своим ингибирующим свойствам они намного превосходят все известные синтетические ингибиторы.

В последнее время интенсивно исследуется интеракция между важным для обмена веществ пищеварительным ферментом - трипсином (T) и натуральными ингибиторами трипсина (ИТ).

Изучение изменения энзиматической активности $\mathrm{T}$ in vivo и in vitro связано $\mathrm{c}$ выяснением влияния натуральных ИТ на его активность. Синтезируемый в животном организме (панкреасе) T начиная с момента его образования находится в близком и постоянном соприкосновении с подавляющими активность Т протеинами. Это взаимодействие кончается в пищеварительном тракте.

Поскольку ИТ обнаружены в тканях, не содержащих доступных для ингибирования ферментов, то можно предположить, что действие ИТ не ограничивается панкреасом и пищеварительным трактом.

Данные ряда исследований позволяют сделать предположение, что кроме селективного ингибирования протеолитических ферментов ИТ могут выполнять в их отношении и другие функции $\left[{ }^{4-6}\right]$. Интересны данные о влиянии введенных с едой натуральных ИТ на физиологические показатели оргағизма подопытных животных $\left[{ }^{7-9}\right]$.

Целью настоящей работы является изучение автокатализа Т, связанного с соевым ИТ (СТИ), в зависимости от весового соотношения между ферментом и ингибитором в условиях минимальной и максимальной активности Т. Некоторые аспекты этой проблемы изучены нами ранее, а результаты опубликованы в кратких сообщениях $\left[{ }^{10-12}\right]$.

\section{Методика}

Реагенты. Основным объектом исследования служил кристаллический Т фирмы «Спофа». Для изучения автолиза Т применяли СТИ фирмы «Реанал».

При проведении экспериментальной части работы использовались неочищенные имеющиеся в продаже Т и СТИ.

Смесь трипсина и ингибитора трипсина из бобов сои (Т-СТИ-комплексы) составлялись в шести различных весовых соотношениях компонентов - $8: 1,4: 1,2: 1,1: 1,1: 2,1: 4$. Одну серию Т-СТИ-комплексов (т. н. неавтолизованные Т-СТИ-комплексы) растворяли в $0,1 \mathrm{M}$ формиатном буфере ( $\mathrm{pH} 3,2)$, другую в таких же количествах и соотношениях (т. н. автолизованные Т-СТИ-комплексы) - в 0,1 M боратном буфере $(\mathrm{pH} 8,6)$ и инкубировали в течение 3,5 ч при температуре $35^{\circ} \mathrm{C}$. Автолиз заканчивали добавлением формиатного буфера до достижения в растворе $\mathrm{pH} 3,2$. 
Определение энзиматической активности. Энзиматическую активность Т в растворах, в автолизатах и в Т-СТИ-комплексах оценивали по интенсивности гидролиза казеина (по Хаммарстену, «Реанал») и этилового эфира N- $\alpha$-бензоил-L-аргинина (БАЕE, «Реанал») [13, 14]. Определения активности проводили в диапазоне волн 280 (казеин) и 253-254 ми (БАЕЕ) с помощью УФ-спектрофотометра «Spektromom 201».

Гель-фильтрация на сефадексах. При гель-фильтрации нативного Т, автолизованного Т, СТИ и Т-СТЙ-комплексов использовали установку, состоящую из колонны $(1,2 \times 140 \mathrm{~cm})$, сосуда элюента и фракционного коллектора «Fractiomat OE-604» (Венгрия). Для наполнителя колонны в основном применяли сефадекс G-100 («Pharmacia»).

В большинстве случаев фракционирования в качестве элюента применяли $0,1 M$ формиатный буфер (pH 3,$2 ; \mu=0,5)$. При проверке стабильности Т-СТИ-комплексов использовали $0,5 \mathrm{M}$ фосфатный буфер $(\mathrm{pH} 8,4, \mu$ 0,5). При гель-фильтрации во всех случаях в колонну вносили предварительно центрифугированный (6000 об/мин) раствор, который содержал 2,5-25 мг исследуемой пробы (Т, СТИ, Т-СТИ-комплекс). Величина фракций составляла 1 мл. Содержание белка во фракциях определяли с помощью оптической плотности в диапазоне 280 м н на ультрафиолетовом спектрофотометре.

\section{Результаты и обсуждение}

Сравнение энзиматической активности Т в Т-СТИ-комплексах. Энзиматическая активность Т в Т-СТИ-комплексах с различными соотношениями компонентов определялась в условиях близких к минимальной $(\mathrm{pH} 3,2)$ и максимальной $(\mathrm{pH} 8,6)$ активности энзима, т. е. до и после автолиза. Строгое соблюдение аналогичных условий опыта (pH, температура и продолжительность автолиза, использование одинаковых соотношений и весовых количеств реагентов) позволило сравнить полученные данные между собой (рис. 1).

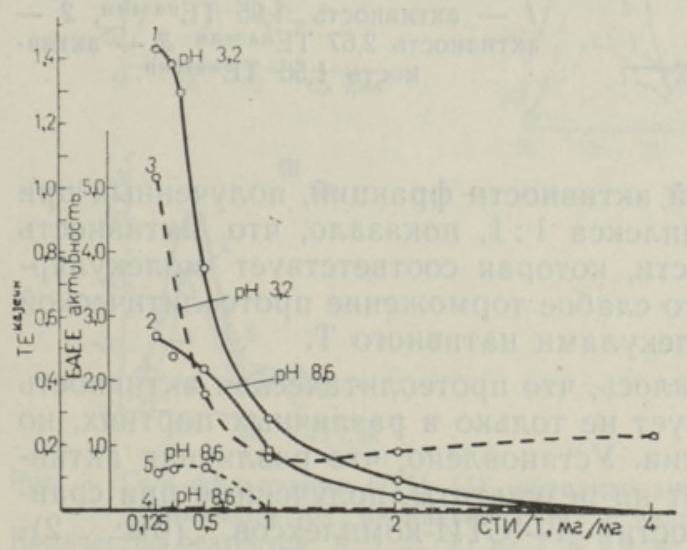

Рис. 1. Влияние СТИ на энзиматическую активность $\mathrm{T}$ при различных соотношениях компонентов.

1 и 2 - протеолитическая активность комплексов, 3 и 4 - эстеразная активность комплексов, 5 - протеолитическая активность несвязанного с СТИ трипсина (количество Т эквивалентны количествам, применяемым в комплексах).

Из рис. 1 выясняется, что протеолитическая активность Т в Т-СТИ-комплексах вследствие автолиза существенно уменьшилась во всех соотношениях фермента 'и ингибитора, за исключением соотношения $1: 1$ и в некоторой степени $2: 1$ и $1: 2$. Уменьшение протеолитической активности у Т, не связанного с СТИ, при автолизе было более значительным, чем у Т, связанного с СТИ, или даже полностью исчезала (кривая 5). Данные об эстеразной активности в комплексах показывают, что активность при автолизе во всех исследованных соотношениях исчезла полностью (кривые 3 и 4). Следовательно, можно сказать, что автолиз воздействует на отдельные формы энзиматической активности Т, связан- 
ного с СТИ, различно; в то время как эстеразная активность во всех компонентных соотношениях отсутствует, протеолитическая активность уменьшается существенно, но не полностью.

При избытке Т в комплексах $(8: 1,4: 1)$ протеолитическая активность уменьшается в основном вследствии автолитического распада молекул Т, не связанных с ингибитором. В этих условиях добавление СТИ ингибирует активность Т не более чем на 50-60\%. При существенном избытке СТИ (1:4) все молекулы Т связаны с ингибитором, что пораждает $100 \%$-ный спад активности и торможение автолиза. При соотношении Т и СТИ 1:1 сохранение протеолитической активности лучшее по сравнению с активностью неавтолизованного Т-СТИ-комплекса. Тенденция к сохранению протеолитической активности в автолизованных комплексах 1:1 наблюдалась и в том случае, когда весовые количества обеих компонентов увеличивались в пять или десять раз. Из этого следует, что описанный эффект при применении данного метода носит закономерный характер и действителен только для протеолитической активности Т. Обстоятельство, что протеолитическая активность 2,5 ме Т

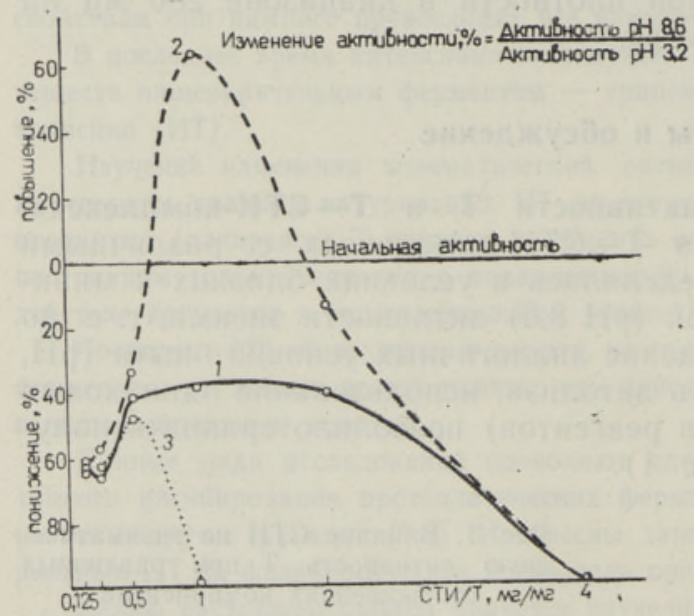
(соответствует количеству Т в $1: 1$ комплексах), не связанного с ингибитором, при автолизе совсем исчезла, является доказательством того, что т. н. тенденция сохранения протеолитической активности характеризует только связанный с ингибитором Т.

Рис. 2. Влияние СТИ на активность препаратов Т с разной протеолитической активностью (активность определяли на 5 мг Т).

1 - активность 1,95 ТЕказенв, 2 активность 2,67 TEказенн, 3 - активность 1,56 ТЕказенв.

Определение протеолитической активности фракций, полученных при гель-фильтрации автолизата комплекса $1: 1$, показало, что активность полностью сосредоточена в области, которая соответствует молекулярному весу Т. Из этого следует, что слабое торможение протеолитической активности все же связано с молекулами нативного Т.

Из результатов опытов выяснилось, что протеолитическая активность продажных препаратов Т варьирует не только в различных партиях, но и в рамках одной и той же партии. Установлено, что различная активность исходного Т заметно влияет на результаты, полученные при сравнении энзиматической активности Т-СТИ-комплексов (рис. 2). Несмотря на то что данные трех опытов (кривые $1-3$ ) являются несколько различными, они указывают на одно - при весовых соотношениях $2: 1$ и $1: 1$ наблюдается тенденция к бо́льшему сохранению протеолитической активности и в одном случае даже к возрастанию его (крнвая 2).

Учитывая все приведенные данные, можно полагать, что присутствие подходящего количества СТИ содействует сохранению протеолитической активности Т при автолизе. 

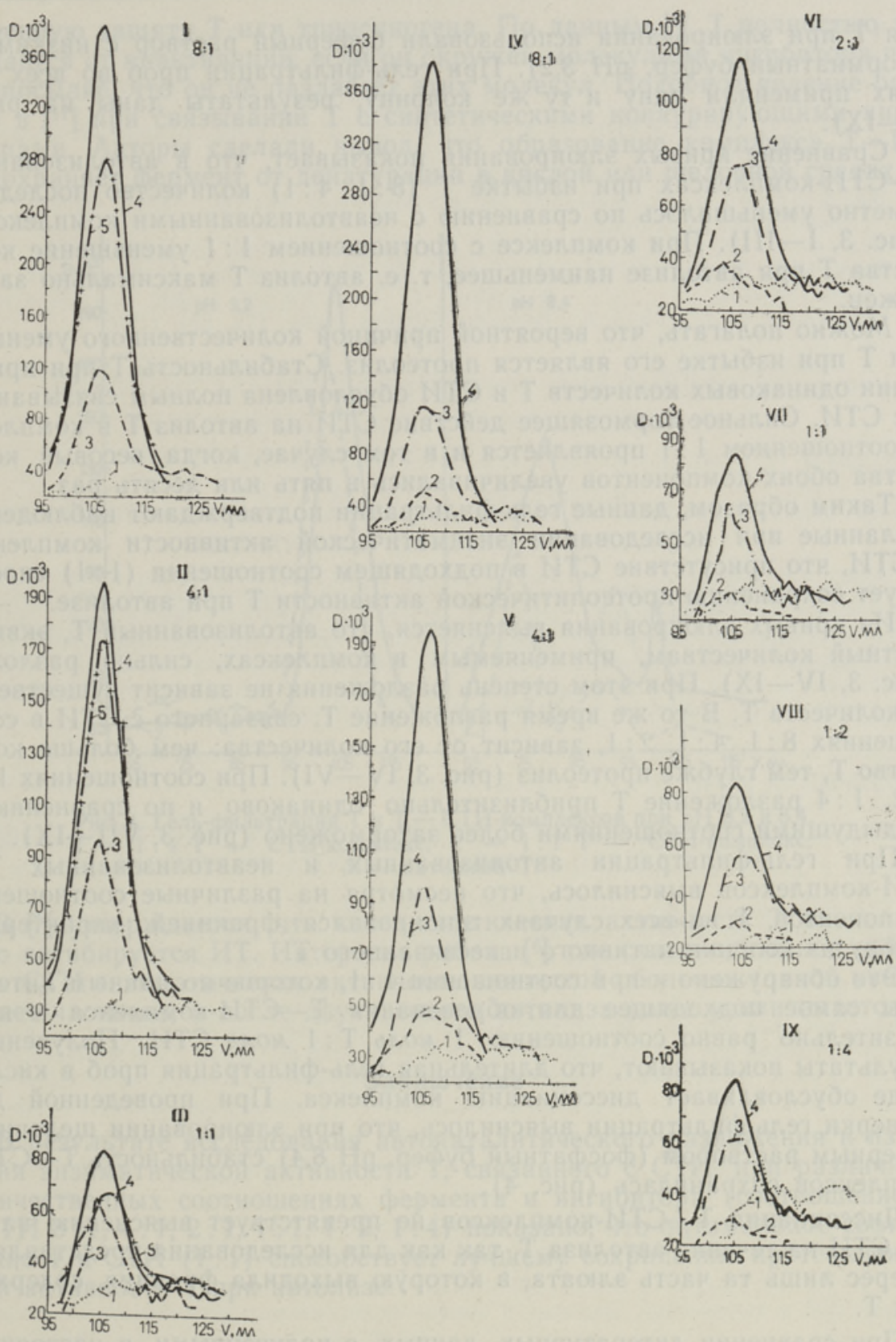

Рис. 3. Гель-фильтращия СТИ (1), автолизованного Т (2), автолизованных Т-СТИкомплексов (3), нативного Т (4) и неавтолизованных комплексов (5).

Количества реагентов: $8: 1-20$ ма Т и 2,5 ма СТИ; $4: 1-10$ мг Т и 2,5 мг СТИ; $2: 1-5$ ма Т и 2,5 ма СТИ; $1: 1-2,5$ ма Т и 2,5 ма СТИ; $1: 2-2,5$ ма Т и 5 ма СТИ; $1: 4-2,5$ ме Т и 10 ме СТИ.

Гель-фильтрация Т-СТИ-комплексов. Для выяснения действия СТИ на ход автолиза трипсина Т-СТИ-комплексы и компоненты комплексов исследовались гель-фильтрацией на сефадексах. Весовые количества изучаемых компонентов были эквивалентны количествам, применяемым в Т-СТИ-комплексах. Для торможения автокаталического разложе- 
ния Т при элюировании использовали буферный раствор с низким рН (формиатный буфер, pH 3,2). При гель-фильтрации проб во всех случаях применяли одну и ту же колонну, результаты даны на рис. 3 $(\mathrm{I}-\mathrm{IX})$.

Сравнение кривых элюирования показывает, что в автолизованных Т-СТИ-комплексах при избытке Т $(8: 1,4: 1)$ количество последнего заметно уменьшилось по сравнению с неавтолизованными комплексами (рис. 3, I-III). При комплексе с соотношением 1:1 уменьшение количества Т при автолизе наименьшее, т. е. автолиз Т максимально заторможен.

Можно полагать, что вероятной причиной количественного уменьшения Т при избытке его является протеолиз. Стабильность Т при применении одинаковых количеств Т и СТИ обусловлена полным связыванием Т с СТИ. Сильное тормозящее действие СТИ на автолиз Т в комплексе с соотношением 1:1 проявляется и в том случае, когда весовые количества обоих компонентов увеличивались в пять или десять раз.

Таким образом, данные гель-фильтрации подтверждают наблюдения, сделанные при исследовании энзиматической активности комплексов Т-СТИ, что присутствие СТИ в подходящем соотношении (1:1) способствует сохранению протеолитической активности Т при автолизе.

Из кривых элюирования выясняется, что автолизованный Т, эквивалентный количествам, применяемым в комплексах, сильно разложен (рис. 3, IV-IX). При этом степень разложения не зависит существенно от количеств Т. В то же время разложение Т, связанного с СТИ в соотношениях $8: 1,4: 1,2: 1$, зависит от его количества: чем больше количество T, тем глубже протеолиз (рис. 3 , IV-VI). При соотношениях $1: 1$, $1: 2,1: 4$ разложение Т приблизительно одинаково и по сравнению с предыдущими соотношениями более заторможено (рис. 3, VII-IX) .

При гель-фильтрации автолизованных и неавтолизованных ТСТИ-комплексов выяснилось, что несмотря на различные соотношения компонентов, Т во всех случаях элюировался фракцией, характерной выходу из колонки нативного и несвязанного Т.

Это обнаружено и при соотношении $1: 1$, которое по данным литературы самое подходящее для образования Т-СТИ-комплекса и приблизительно равно соотношению 1 моль Т: 1 моль СТИ. Полученные результаты показывают, что длительная гель-фильтрация проб в кислой среде обусловливает диссоциацию комплекса. При проведенной для проверки гель-фильтрации выяснилось, что при элюировании щелочным буферным раствором (фосфатный буфер, $\mathrm{pH} 8,4$ ) стабильность Т-СТИкомплексов сохранилась (рис. 4).

Диссоциация Т-СТИ-комплексов не препятствует выяснению влияния СТИ на течение автолиза Т, так как для исследования представляла интерес лишь та часть элюата, в которую выходила фракция, содержащая $\mathrm{T}$.

При сравнении литературных данных с полученными в настоящей работе результатами было обнаружено отсутствие прямых указаний на подобные сведения, что, очевидно, объясняется различным подходом к данной проблеме. Однако необходимо отметить некоторые данные о сохранении или даже увеличении при автолизе энзиматической активности связанного или несвязанного с ингибитором Т.

Интересна работа В. Мосолова и М. Логиновой, где из автолизата Т гель-фильтрацией была выделена одна низкомолекулярная фракция, эстеразная активность которой оказалась даже выше, чем у исходного Т $\left.{ }^{15}\right]$. По мнению Дэнуэль $\left[{ }^{16}\right]$, малые количества ИТ способны полностью тормозить энзиматическую активность Т и тем самым вызывать т. н. 
временную защиту Т или трипсиногена. По данным $\left[{ }^{4}\right]$, Т полностью защищается от инактивации, если он окружен молекулами ингибитора при предпосылке, что он не разлагает этих молекул. Подобное явление описано в $\left[{ }^{17}\right]$ при связывании Т с синтетическими конкурирующими ингибиторами. Авторы сделали вывод, что образование комплекса Т-ИТ предохраняет фермент от денатурации в кислой или щелочной средах.

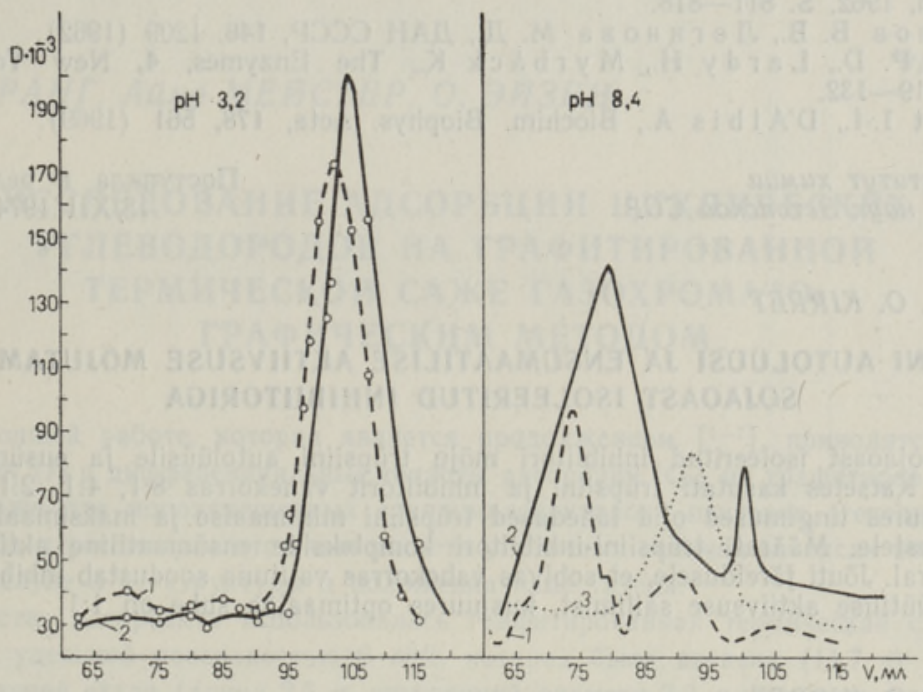

Рис. 4. Гель-фильтрация Т и Т - СТИ-комплексов при рН 3,2 и 8,4. 1 - 1:4 Т - СТИ-комплекс, 2 - 1:1 Т - СТИ-комплекс, 3 - нативный Т.

В [5] утверждается, что казеинолитическая активность Т не полностью ингибируется ИТ. Интересна работа [ $\left.{ }^{6}\right]$, где сказано, что под действием СТИ энзиматическая активность слизистой оболочки-тонкой кишки падает частично, а после двухчасового автолиза даже увеличивается.

\section{Заключение}

В результате исследования автокаталитического разложения и изменения энзиматической активности Т, связанного с СТИ, при различных количественных соотношениях фермента и ингибитора (соотношение $\mathrm{T}$ и СТИ $8: 1,4: 1,2: 1,1: 1,1: 2,1: 4)$ показано, что оптимальное соотношение Т и СТИ $(1: 1)$ способствует лучшему сохранению протеолитической активности Т при автолизе.

\section{Л ИТ Е Р А Т У РА}

1. Laskowski M., La skowski M. Jr., Advances Protein Chem., 9, 203 (1954).

2. Vogel R., Trautschold I., Werle E., Natürliche Proteinasen-Inhibitoren. Thieme Verlag, Stuttgart, 1966, S. 8-75.

3. Мосолов В. В., Протеолитические ферменты. М., 1971, с. $275-312$.

4. Pudles J., B a chellerie D., Arch. Biochem. Biophys., 128, 133 (1968).

5. Werle E., Trautschold I., Haendle H., Fritz H., Ann. N. Y. Acad. Sci., 146, 464 (1968)

6. B a intne r K., Juh a sz S., Acta physiol., Acad. sci. hung., 40, 179 (1971).

7. H a in es P. C., L y m a n R. L., J. Nutr., 74, 445 (1961).

8. Geratz J. G., Hurt J. P., Am. J. Physiol., 219, 705 (1970). 
9. Konijn A. M., B irk Y., Gugg en he im K., Am. J. Physiol., 218, 1113 (1970).

10. He inlo H., ENSV TA Toim., Keemia, Geoloogia, 21, 176 (1972).

11. Heinlo H., Pihelg a s V., K irret O., ENSV TA Toim., Keemia, Geoloogia, 23, 88 (1974).

12. Heinlo H., Kleemeier T., Kirret O., ENSV TA Toim., Keemia, Geoloogia, 23, $264(1974)$

13. Kunitz M., J. Gen. Physiol., 30, 291 (1947).

14. B ergmeyer H. U., Methoden der enzymatischen Analyse, Verlag Chemie, Weinheim, 1962, S. $811-818$.

15. Мосолов В. В., Л ог и нов а М. Д., ДАН СССР, 146, 1209 (1962).

16. B oyer P. D., La rdy H., Myrbäck K., The Enzymes, 4, New York, 1960, p. $119-132$.

17. B echet I.-I., D'A 1 b is A., Biochim. Biophys. Acta, 178, 561 (1969).

\section{Институт химии \\ Академии наук Эстонской ССР \\ Поступила в редакцию}

H. HEINLO, O. KIRRET

\section{TRUPSIINI AUTOLUUSI JA ENSUMAATILISE AKTIIVSUSE MOJUTAMISEST SOJAOAST ISOLEERITUD INHIBIITORIGA}

Uuriti sojaoast isoleeritud inhibiitori mõju trüpsiini autolüüsile ja ensümaatilisele aktiivsusele. Katsetes kasutati trüpsiini ja inhibiitorit vahekorras 8:1, 4:1, 2:1, 1:1, 1:2 ja 1:4, kusjuures tingimused olid lähedased trüpsiini minimaalse ja maksimaalse aktiivsuse tingimustele. Määrati trüpsiini-inhibiitori komplekside ensümaatiline aktiivsus erineva $\mathrm{pH}$ korral. Jõuti järeldusele, et sobivas vahekorras valituna soodustab inhibiitor trüpsiini proteolüütilise aktiivsuse säilimist, kusjuures optimaalne suhe on 1:1.

\section{H. HEINLO, O. KIRRET}

\section{ABOUT THE INFLUENCE OF THE SOYBEAN TRYPSIN INHIBITOR ON THE AUTOLYSIS AND ENZYMATIC ACTIVITY OF TRYPSIN}

The paper deals with results of an investigation of the influence of the soybean trypsin inhibitor on the autolysis and enzymatic activity of trypsin. Investigations were carried out with different weight relations of trypsin and inhibitor $(8: 1,4: 1,2: 1,1: 1$, $1: 2,1: 4)$. The experiment conditions were near to the minimum and maximum ones of trypsin enzymatic activity. The enzymatic activity of trypsin - inhibitor complexes at different $\mathrm{pH}$ was determined. It was found that the presence of inhibitor in optimal relation promotes the preservation of proteolytic activity of trypsin. The preservation of activity is most favourable at relation 1:1 of trypsin and inhibitor. 